\title{
Temperature, Moisture, and Seed Treatment Effects on Rhizoctonia solani Root Rot of Soybean
}

\author{
A. E. Dorrance, Assistant Professor, Department of Plant Pathology; M. D. Kleinhenz, Assistant Professor, De- \\ partment of Horticulture and Crop Science; S. A. McClure, Research Assistant, Department of Plant Pathology, and \\ N. T. Tuttle, former Graduate Research Assistant, The Ohio State University, OARDC, Wooster OH 44691-4096
}

\begin{abstract}
Dorrance, A. E., Kleinhenz, M. D., McClure, S. A., and Tuttle, N. T. 2003. Temperature, moisture, and seed treatment effects on Rhizoctonia solani root rot of soybean. Plant Dis. 87:533538 .

The effects of temperature and soil moisture on infection and disease development by Rhizoctonia solani on soybean were studied individually. In addition, the anastomosis group of $R$. solani isolates recovered from soybean from 35 fields in 15 counties was determined. All of the 44 isolates recovered in this study were AG-2-2 IIIB. Five isolates of $R$. solani were able to infect and colonize soybean roots and hypocotyls at $20,24,28$, and $32^{\circ} \mathrm{C}$ in growth chamber studies. The temperatures evaluated in this study were not limiting to the isolates tested. In greenhouse studies, nine $R$. solani isolates and a noninoculated control were evaluated at $25,50,75$, and $100 \%$ soil moisture holding capacity (MHC). Root weights were greater and percent stand averages higher at 50 and $75 \%$ than at 25 or $100 \%$ MHC; however, as percentage of control, the main effect on percent moisture for percent stand, plant height, or root weight was not significant. There were significant differences among the isolates for the percent stand, root rot rating, and root fresh weight of soybean in each study. In both temperature and moisture studies, the $R$. solani isolates could be separated as predominantly causing (i) seed rot, as detected by greatly reduced plant stand; (ii) root rot generally having no effect on plant stand but a high root rot rating and low root weight; or (iii) hypocotyl lesions, having no effect on plant stand, a low root rot score, and a high number of red lesions on the hypocotyl. In the greenhouse seed treatment evaluations of five fungicides, there was no fungicide by isolate interaction using these pathogenic types of $R$. solani. None of the seed treatments evaluated in this study provided $100 \%$ control of the four isolates tested. Due to the wide range of environmental factors that permit $R$. solani infection and disease on soybeans, other control measures that last all season, such as host resistance, should be emphasized.
\end{abstract}

Rhizoctonia solani can cause pre- and postemergence damping off, root rot, and hypocotyl lesions on soybeans in the United States as well as web blight in the southern United States (20). Seedling diseases caused by $R$. solani, Pythium spp., and/or Fusarium spp. ranked fourth overall among diseases causing losses on soybeans in the United States during 1996 to 1998 (19). R. solani along with Pythium spp. and Phytophthora sojae were identified as the major causal agents in soybean seedling disease in Iowa (14). Epidemics of $R$. solani damping-off have occurred in soybeans, with reported yield losses as high as $50 \%$ (16).

$R$. solani is divided into anastomosis groups (AG) based on hyphal anastomosis and cultural characteristics $(4,12,15)$. Isolates within an AG may have similar characteristics, such as the type of symptoms

Corresponding author: A. E. Dorrance

E-mail: dorrance.1@osu.edu

Accepted for publication 9 December 2002.

Publication no. D-2003-0228-01R

(C) 2003 The American Phytopathological Society produced on a host and host preferences $(1,15)$. In Florida and the Red River Valley (North Dakota and Minnesota), AG-4 and more recently AG-5 were the predominant AG groups of $R$. solani found to cause disease on soybeans $(11,13)$. In Illinois, two isolates of AG-2-2 that were pathogenic on both corn and soybeans were identified (8). Previous surveys of $R$. solani in soybean in Ohio have identified only AG-2-2 IIIB (10).

An understanding of the role environmental factors have on the infection and survival of any root pathogen is necessary to develop cultural disease management practices as well as assays that evaluate host resistance or efficacy of seed treatments. The impacts of temperature and soil moisture and subsequent disease development on infection by $R$. solani have been inconsistent in experimental systems with soybean and other crops. Rainfall followed by cool weather in a "subnormal" rainfall season (16) and high temperature and soil moisture under greenhouse conditions (7) have both been reported to favor Rhizoctonia disease development in soybean. Rhizoctonia infection of red kidney bean was maximal at $27^{\circ} \mathrm{C}$ and $20 \%$ soil moisture holding capacity in growth chamber studies (18). But soil moisture levels from -0.1 to $-1.5 \mathrm{MPa}$ had little effect on $R$. solani AG-2-1 infection of canola seedlings in both field and greenhouse studies (17). These inconsistent results provide incentive to develop improved methodologies for identifying the exact roles of temperature and root zone moisture on infection and disease development.

Documenting the independent and interactive effects of soil moisture and temperature on plant disease is essential for developing effective management strategies or screening for host resistance. Temperature is relatively easy to control experimentally, especially in climate-controlled chambers. In contrast, soil moisture levels can be more difficult to regulate. For this work, we employed a novel method for managing soil moisture levels that is highly repeatable and offers a fine level of control over root zone moisture levels, especially in large-scale experiments (5). In this way, we were able to test soil moisture effects on $R$. solani infection and disease development with levels of accuracy and precision unknown in earlier studies.

Seed treatment fungicides have been developed recently to help manage infections of seed and seedlings by $R$. solani, and many are labeled for soybeans. Efficacy of specific fungicides against $R$. solani was found to be variable and dependent on the AG in amended agar plate assays (9). Isolates representing four different AGs were variable in sensitivity to carboxin, PCNB, and triadimefon, while most isolates were sensitive to iprodione (9). Efficacy evaluations completed in greenhouse and field studies will be dependent on environmental conditions that are favorable for disease development.

The objectives of this study were to determine (i) if a change has occurred in the $R$. solani AGs that attack soybeans in Ohio, (ii) temperature and moisture levels that most favor Rhizoctonia disease development in soybean seeds and seedlings, and based on these results (iii) the efficacy of fungicide and biological seed treatments to $R$. solani AGs prevalent in Ohio.

\section{MATERIALS AND METHODS}

Isolates. Soybean plants with brick red hypocotyl lesions were collected from fields during the spring and late summer of 1998, 1999, and 2000. The hypocotyls and roots were washed with detergent and 
rinsed for 10 to $20 \mathrm{~min}$ in running tap water. Tissues were surface disinfested by placing small sections (5 to $15 \mathrm{~mm}$ ) in $10 \%$ sodium hypochlorite for $1 \mathrm{~min}$, then blotted dry with sterile paper toweling. Sections from the edge of the lesion were cut from the hypocotyl and placed on acidified potato dextrose agar (APDA). $R$. solani AG tester isolates were obtained from B. Nelson, North Dakota State University (AGs 1-1A, 1-IB, 1-IC, 2-1, 2-2, 3, 4, 5, 6, 7, 8, 9, and BI) and C. Windels, University of Minnesota, NW Experiment Station (AGs 1, 2-1, 2-2, 2-2 IIIB, 3, 4, and 5). AGs were determined by pairing unknown isolates with known AG tester isolates on thin water agar plates $(4,15)$. Isolates that anastomosed with the AG-2-2 and AG-2-2 IIIB tester were evaluated for growth at $35^{\circ} \mathrm{C}(12,15)$.

Inoculum production. $R$. solani isolates used in these studies are listed in Table 1. $R$. solani colonized oats were produced by first soaking $600 \mathrm{ml}$ of oats with $500 \mathrm{ml}$ of water in 2.8-liter Erlenmeyer flasks overnight. The flasks with oats were then autoclaved for $1 \mathrm{~h}$ each on two consecutive days. From a 5- to 7-dayold $R$. solani colony on water agar, three to five plugs, $5 \mathrm{~mm}$ in diameter, were cut and added to each flask. Once the colonies on the oats were approximately $25 \mathrm{~mm}$ in diameter, the flasks were shaken daily for 3 weeks to ensure thorough colonization. After the oats were well colonized, inoculum was placed on brown paper on laboratory benches to air dry. The inoculum was mixed and broken apart into individual kernels daily for 3 days, then placed in plastic bags and stored at $4{ }^{\circ} \mathrm{C}$ until used. Control treatments or noninoculated did not have any oats added to the pots. Fungus gnats have been a limiting factor in some earlier experiments on the noncolonized oats (A. E. Dorrance, unpublished data).

Temperature effects. Four growth chambers, with temperatures set at 20, 24, 28 , or $32^{\circ} \mathrm{C}$, were used to evaluate the effects of temperature on $R$. solani disease development. $R$. solani isolates 98-0, 99-8, 99-13, 99-15, Rs91-1, and a noninoculated control were used in this experiment. The experiment was arranged in a split-plot design with the temperatures (growth chambers) as the whole plot and the isolates as the subplot with three pots per isolate as observations. The experiment was repeated three times, which served as replication. Coarse vermiculite (Therm-ORock, New Eagle, PA) was added to 14cm-diameter pots until they were twothirds full. Twelve seeds of the soybean cultivar Resnik were placed on the surface of the vermiculite with $30 \mathrm{ml}$ of $R$. solani colonized oats or a noninoculated control. The soybean seed and inoculum were covered with approximately $2.5 \mathrm{~cm}$ of vermiculite and placed in the growth chambers at the set temperatures and light/dark cycle of $12 \mathrm{~h}$. Pots were watered twice daily. Data were collected after 3 weeks on the number of plants that emerged, number of plants with lesions, average plant height, top fresh weight, and root rot rating. The root rot rating scale was as follows: $1=$ no root rot; $2=1$ to $33 \%$ of roots with visible lesions or root rot; $3=$ approximately 33 to $50 \%$ of the roots rotted or damaged; $4=50$ to $80 \%$ of the roots rotted; and $5=$ preemergence damping-off and few if any roots.

Soil moisture effects. Infection and disease development following simultaneous exposure of soybean seeds and plants to nine $R$. solani isolates (Rs91-1, 98-0, 98-1, $99-5,99-8,99-11,99-12,99-13,99-15)$ or a noninoculated control at four root zone moisture levels $(25,50,75$, or $100 \%$ moisture holding capacity) were studied in the greenhouse. Treatments based on soil moisture holding capacity (MHC) were selected primarily due to their reliability and ease of use. However, they also facilitate the ability to infer potential treatment effects on other soil types and the communication of project results to diverse audiences. The soil mix consisted of a Wooster silt loam soil supplemented 1:1 ( $\mathrm{vol} / \mathrm{vol})$ with washed quartz sand passed through a

Table 1. Rhizoctonia solani isolates and anastomosis group (AG), recovered from Ohio soybean production fields, used in studies to evaluate the effects of temperature, moisture, and seed treatments on infection of soybeans

\begin{tabular}{llll}
\hline Isolate $^{\mathbf{a}}$ & AG & Pathogenicity $^{\mathbf{b}}$ & Location (county) \\
\hline Rs91-1 & Unknown & Hypocotyl and root & Unknown \\
$98-0$ & AG-2-2 IIIB & Hypocotyl & Clinton \\
$98-1$ & AG-2-2 IIIB & Root & Wyandot \\
$99-5$ & AG-2-2 IIIB & Hypocotyl & Morrow \\
$99-8$ & AG-2-2 IIIB & Root & Henry \\
$99-11$ & AG-2-2 IIIB & Root and seed & Marion \\
$99-12$ & AG-2-2 IIIB & Hypocotyl and seed & Pickaway \\
$99-13$ & AG-2-2 IIIB & Root & Morrow \\
$99-15$ & AG-2-2 IIIB & Seed and root & Wood \\
$99-17$ & AG-2-2 IIIB & Seed & Morrow \\
\hline
\end{tabular}

a Designations are based on year and sequential number of isolates as recovered from plants with the exception of Rs91-1. This isolate was maintained at the Department of Plant Pathology, OARDC Wooster, previously by A. F. Schmitthenner.

${ }^{\mathrm{b}}$ Pathogenicity was determined by planting soybeans in soil or vermiculite with $R$. solani colonized oats. Root rot and hypocotyl ratings were taken 2 to 3 weeks following inoculations.
$3 \times 3 \mathrm{~mm}$ mesh screen. Soil was air-dried in the greenhouse for 2 months prior to use. Pots $(9 \mathrm{~cm}$ diameter) were prepared by placing a $4 \mathrm{~cm}^{2}$ section of paper towel in the bottom followed by $285 \mathrm{~g}$ of the soil mix. Six seeds of 'Resnik' soybean were placed on top of the soil mix with $30 \mathrm{~cm}^{3}$ of colonized oat kernel inoculum placed in direct contact with the seed. Seed and inoculum were then covered with $2.5 \mathrm{~cm}$ of soil mix.

Gravimetric measurements were used in preliminary studies to determine the moisture holding capacity of the rooting medium. Identically prepared pots lacking seed were weighed, saturated with distilled $\mathrm{H}_{2} \mathrm{O}$, allowed to drain overnight, and reweighed. Each pot held approximately $86 \mathrm{~g}$ $\mathrm{H}_{2} \mathrm{O}$, calculated as the average difference between the presaturation and final weight of five pots. Root zone moisture treatments were set at $25,50,75$, and $100 \%$ of moisture holding capacity (MHC). Therefore, to initiate this study of root zone moisture level effects on $R$. solani infection and disease development, $21,43,65$, or $86 \mathrm{ml}$ of $\mathrm{H}_{2} \mathrm{O}$ was added to randomly selected pots, then allowed to equilibrate overnight. Thereafter, target root zone moisture levels were maintained using a variation of the method described by Kleinhenz and Palta (5). Fresh $\mathrm{H}_{2} \mathrm{O}$ was delivered continuously to each pot via a siphon established through 0.8-mm, 1.6-ID microbore tubing (Tygon Formula S-54-HL, Norton Performance Plastics Corp., Akron, $\mathrm{OH}$ ). The single line serving each pot was either 2 or $4 \mathrm{~m}$ long and situated so that $\mathrm{H}_{2} \mathrm{O}$ dripped freely into the medium approximately $2 \mathrm{~cm}$ from the edge of the pot. Water was held in opaque 19- or 57-liter reservoirs located in the study area. Target $\mathrm{H}_{2} \mathrm{O}$ delivery rates were achieved by varying the hydraulic head (distance in height between the water level in the reservoir and the soil line in the pot) and length of tubing between $\mathrm{H}_{2} \mathrm{O}$ reservoirs and pots. The approximate hydraulic head height in relation to the soil line in the pot and tubing length for each treatment were: $2.0 \mathrm{~cm}$ and $4 \mathrm{~m}(25 \%$ MHC), $16 \mathrm{~cm}$ and $2 \mathrm{~m}$ (50\% MHC), $15 \mathrm{~cm}$ and $2 \mathrm{~m}(75 \% \mathrm{MHC})$, and $4 \mathrm{~cm}$ and $2 \mathrm{~m}$ (100\% MHC). Water reservoirs were refilled to target levels regularly to minimize reductions in the hydraulic head over long time periods. Pots were weighed four to six times during each experiment to gauge root zone moisture levels, and delivery rates were adjusted, if necessary.

The factorial set of treatments (nine $R$. solani isolates plus a noninoculated control $x$ four root zone moisture levels) were arranged in a randomized block design with four, single-pot replications per treatment. The experiment was repeated twice. Percent plant emergence, plant height, fresh root weight, and root rot ratings (1 to 5 scale as described above) were recorded 2 weeks after seeding on plants in early V1 growth stage. 
Seed treatment evaluations. Soybean seed of the cultivar Resnik was treated with one of four fungicides or a biological product, all currently labeled for soybean, or were not treated. The materials were applied at the following rates per $100 \mathrm{~kg}$ of seed: $260.3 \mathrm{ml}$ of Rival (19.8\% captan plus $8.4 \%$ PCNB plus $1.0 \%$ thiabendazole; Gustafson, Plano, TX); $443 \mathrm{ml}$ of Stilletto (10\% carboxin plus $10.0 \%$ thiram plus $1.62 \%$ metalaxyl; Trace Chemicals LLC, Pekin, IL); $443 \mathrm{ml}$ of Vitavax (16.7\% carboxin, $1.2 \%$ imazalil plus $1.5 \%$ thiabendazole; Gustafson); $5.2 \mathrm{ml}$ of Maxim (40.3\% fludioxonil; Syngenta, Raleigh, NC); or $311.9 \mathrm{~g}$ of $\mathrm{T}-22^{\mathrm{TM}} \mathrm{PB}$ (Trichoderma harzianum, strain T22; Bioworks, Inc., Geneva, NY). The soil used in this study was the same as for the soil moisture studies described above. Six seeds were planted in $9-\mathrm{cm}$ plastic pots with $30 \mathrm{~cm}^{3}$ of inoculum per pot of one of the following $R$. solani isolates: 99-8, 99-12, 99-14, and 99-17. The experimental design was a randomized complete block with four replications with two main effects, (i) the four isolates and an noninoculated control and (ii) the four fungicides, biological control product, and a nontreated control, paired in all possible combinations. The daily temperature in the greenhouse during this study ranged from 21 to $27^{\circ} \mathrm{C}$. Pots were watered two or three times a day to maintain high levels of moisture. Data were collected 3 weeks after planting when the plants were early V1 growth stage, on plant height, number of plants emerged, root rot rating as described above, and fresh root weight. This experiment was repeated twice.

Statistical analysis. Percent emergence, plant height, root and/or shoot fresh weight, and root rot rating were subjected to analysis of variance with the PROC GLM procedure of SAS (SAS Institute, Cary, NC). Root rot ratings were transformed to $R^{*}=\left(R^{1.5}-1\right) / 1.5$ to obtain a linear scale as described by Krause et al. (6). The transformed data were subjected to analysis of variance. The outcome of the analysis of variance was not different for the transformed data compared with the nontransformed data; therefore the analysis of the nontransformed data is presented here. Temperature experiments were analyzed as a split-plot design with temperature and isolate as main plot and subplots, respectively. The three experiments were considered to be replications, and observations within each isolate-temperature treatment were averaged prior to analysis. Experiments for moisture and seed treatment effects were analyzed separately. Fisher's protected least significant difference (LSD) test was used to separate treatment means in all studies.

\section{RESULTS}

Plants with brick red cankers and root rot were collected from 35 fields in 15 counties in northwest and central Ohio during this study. One isolate of $R$. solani was recovered from each of 2, 23, and 19 plants during 1998, 1999, and 2000, respectively. All of the 44 isolates anastomosed with the $R$. solani AG-2-2III B tester isolate. One additional isolate, Rs911 from the Soybean Pathology Collection, Ohio State University, collected during 1991, did not anastomose with any of the tester isolates. All of the AG-2-2 IIIB isolates grew at $35^{\circ} \mathrm{C}$.

Temperature effects. The main effect of temperature was not significant for percent stand or root rot rating for the isolates evaluated in this study (Table 2). There was a significant difference in the number of hypocotyl lesions that developed on the plants $(P=0.014)$ across the temperatures. There were highly significant differences
$(P<0.001)$ among the isolates for all the measured parameters. Among the isolates, 99-15 was a seed and root rotter that had the lowest final percent plant stand $(23.8 \%)$ and produced the highest root rot ratings (4.2) compared with the other isolates and the noninoculated control (Table 3 ). In contrast, $R$. solani isolate 98-0 caused the greatest number of hypocotyl lesions (4.8), reduced final plant stand $(68.8 \%)$, and resulted in a 3.2 root rot rating. Isolate $99-8$ was the least aggressive of all of the isolates, with final stand percentage of $90.7 \%$, a percentage that did not differ from the noninoculated control $(98.4 \%)$.

Moisture effects. As expected, root zone moisture level had a strongly significant $(P<0.001)$ effect on percent stand, plant height, and root fresh weight. More importantly, the method used here clearly distinguished suboptimal, optimal, and supra-optimal root zone moisture levels, based on plant growth. For example, mean root fresh weight was $3.8 \mathrm{~g}$ for plants maintained at both 25 and $100 \%$ soil MHC, while for plants maintained at 50 and $75 \%$ soil MHC, weights were 5.4 and $5.6 \mathrm{~g}$, respectively. Therefore, the effects of the isolates on soybean at the different MHC were analyzed as percentage of the noninoculated control. The main effect of moisture was not significant for the pa-

Table 3. Percent stand, root rot rating, and number of hypocotyl lesions with one of four Rhizoctonia solani isolates and a noninoculated control evaluated in growth chambers at $20,24,28$, and $32^{\circ} \mathrm{C}$

\begin{tabular}{lccc}
\hline Factor & Percent stand & Root rot rating & No. of hypocotyl lesions $^{\text {Isolate }}$ \\
$98-0$ & 68.8 & 3.2 & 4.8 \\
$99-8$ & 90.7 & 1.9 & 2.8 \\
$99-13$ & 63.9 & 3.3 & 2.3 \\
$99-15$ & 23.8 & 4.3 & 0.7 \\
Noninoculated & 98.4 & 1.1 & 0.0 \\
LSD $(P \leq 0.05)^{\mathrm{b}}$ & 20.1 & 0.7 & 2.0 \\
Temperature & & & \\
$20^{\circ} \mathrm{C}$ & 69.6 & 2.9 & 1.1 \\
$24^{\circ} \mathrm{C}$ & 67.2 & 2.7 & 1.7 \\
$28^{\circ} \mathrm{C}$ & 67.9 & 2.7 & 2.6 \\
$32^{\circ} \mathrm{C}$ & 71.7 & 2.7 & 3.0 \\
LSD $(P \leq 0.05)$ & $\mathrm{NS}$ & $\mathrm{NS}$ & 1.8 \\
Means & 69.1 & 2.8 & 2.1 \\
\hline Rot & & 2.8 & \\
\hline
\end{tabular}

a Root rot rating scale was as follows: $1=$ no root rot; $2=1$ to $33 \%$ of roots with visible lesions or root rot; 3 = approximately 33 to $50 \%$ of the roots rotted or damaged; $4=50$ to $80 \%$ of the roots rotted; and 5 = preemergence damping-off and few if any roots.

b LSD stands for least significant difference as determined with Fisher's protected LSD at $P \leq 0.05$.

Table 2. Analysis of variance for effects of temperature on four Rhizoctonia solani isolates on soybeans and a noninoculated control at $20,24,28$, or $32^{\circ} \mathrm{C}$ in growth chamber experiments

\begin{tabular}{|c|c|c|c|c|c|c|c|}
\hline \multirow[b]{2}{*}{ Source } & \multirow[b]{2}{*}{ df } & \multicolumn{2}{|c|}{ Percent stand } & \multicolumn{2}{|c|}{ Root rot rating $^{a}$} & \multicolumn{2}{|c|}{ No. of hypocotyl lesions } \\
\hline & & MS & $\boldsymbol{P}$ & MS & $P$ & MS & $P$ \\
\hline Experiment (E) & 2 & $5,947.7$ & $<0.001$ & 4.672 & 0.004 & 68.156 & $<0.001$ \\
\hline Temperature (T) & 3 & 58.4 & 0.8716 & 0.213 & 0.589 & 11.459 & 0.014 \\
\hline $\mathrm{E} \times \mathrm{T}$ & 6 & 252.9 & & 0.308 & & 1.341 & \\
\hline Isolates (I) & 5 & $10,203.4$ & $<0.001$ & 19.332 & $<0.001$ & 42.45 & $<0.001$ \\
\hline $\mathrm{T} \times \mathrm{I}$ & 12 & 138.5 & 0.9944 & 0.534 & 0.683 & 5.737 & 0.489 \\
\hline Error & 32 & 581.7 & & 0.701 & & 5.869 & \\
\hline
\end{tabular}

a Root rot rating scale was as follows: $1=$ no root rot; $2=1$ to $33 \%$ of roots with visible lesions or root rot; $3=$ approximately 33 to $50 \%$ of the roots rotted or damaged; $4=50$ to $80 \%$ of the roots rotted; and $5=$ preemergence damping-off and few if any roots. 
Table 4. Analysis of variance of percent control for the effects on soybeans from nine Rhizoctonia solani isolates at $25,50,75$, and $100 \%$ of soil moisture holding capacity in two greenhouse experiments

\begin{tabular}{|c|c|c|c|c|c|c|c|}
\hline \multirow[b]{2}{*}{ Source } & \multirow[b]{2}{*}{ df } & \multicolumn{2}{|c|}{ Percent stand } & \multicolumn{2}{|c|}{ Height $^{\mathbf{a}}$} & \multicolumn{2}{|c|}{ Fresh root weight } \\
\hline & & MS & $P$ & MS & $\boldsymbol{P}$ & MS & $P$ \\
\hline Experiment (E) & 1 & $6,394.8$ & 0.472 & $8,636.9$ & 0.399 & 174.3 & 0.890 \\
\hline $\operatorname{Rep}(\mathrm{E})$ & 6 & $10,901.9$ & & $10,485.9$ & & 8314.6 & \\
\hline Moisture (M) & 3 & $5,868.5$ & 0.136 & $6,249.4$ & 0.119 & $30,892.9$ & 0.289 \\
\hline $\mathrm{E} \times \mathrm{M}$ & 3 & $6,100.4$ & 0.124 & $5,633.1$ & 0.152 & $15,307.5$ & \\
\hline Isolate & 8 & $8,124.2$ & 0.010 & $8,013.6$ & 0.012 & $23,649.2$ & 0.001 \\
\hline $\mathrm{M} \times$ isolate & 24 & $1,745.9$ & 0.955 & $1,745.8$ & 0.957 & $2,065.5$ & 0.742 \\
\hline $\mathrm{E} \times$ isolate & 8 & $2,620.2$ & 0.573 & $2,659.3$ & 0.568 & $3,487.9$ & 0.228 \\
\hline $\mathrm{E} \times \mathrm{M} \times$ isolate & 24 & $2,021.5$ & 0.899 & $2,016.7$ & 0.905 & $1,056.6$ & 0.995 \\
\hline Error & 210 & $3,142.4$ & & $3,165.6$ & & $2,614.1$ & \\
\hline
\end{tabular}

a Average height of plants in pot.

Table 5. Percent stand, root rot rating, and fresh root weight with one of 10 Rhizoctonia solani isolates and a noninoculated control evaluated at four moisture holding capacity (MHC) levels in a Wooster silt loam soil in the greenhouse

\begin{tabular}{lccc}
\hline Factor & Percent stand & Root rot rating & Root weight $(\mathbf{g})$ \\
\hline Isolate & & & \\
Rs91-1 & 77.5 & 2.1 & 5.0 \\
$98-0$ & 84.4 & 2.5 & 3.8 \\
$98-1$ & 81.2 & 2.7 & 3.9 \\
$99-5$ & 92.6 & 1.9 & 5.3 \\
$99-8$ & 89.0 & 2.0 & 6.0 \\
$99-11$ & 84.8 & 2.8 & 4.3 \\
$99-12$ & 87.4 & 2.0 & 5.8 \\
$99-13$ & 83.8 & 2.0 & 5.6 \\
$99-15$ & 77.5 & 4.3 & 1.7 \\
Noninoculated & 85.4 & 1.2 & 5.3 \\
LSD $(P \leq 0.05)^{\mathrm{b}}$ & 9.2 & 0.4 & 1.0 \\
MHC & & & \\
$25 \%$ & 74.7 & 2.6 & 3.8 \\
$50 \%$ & 86.4 & 2.2 & 5.4 \\
$75 \%$ & 86.0 & 2.2 & 5.7 \\
$100 \%$ & 73.5 & 2.4 & 3.8 \\
LSD $(P \leq 0.05)$ & $\mathrm{NS}$ & $\mathrm{NS}$ & 0.6 \\
Means & 80.1 & 2.4 & 4.7 \\
\hline
\end{tabular}

${ }^{a}$ Root rot rating scale was as follows: $1=$ no root rot; $2=1$ to $33 \%$ of roots with visible lesions or root rot; $3=$ approximately 33 to $50 \%$ of the roots rotted or damaged; $4=50$ to $80 \%$ of the roots rotted; and 5 = preemergence damping-off and few if any roots.

${ }^{\mathrm{b}}$ LSD stands for least significant difference as determined with Fisher's protected LSD at $P \leq 0.05$.

rameters when analyzed as a percentage of control (Table 4). The availability of free moisture appeared not to be limiting, as root rot occurred at all levels of MHC with all isolates used in this study.

The pathogenicity or aggressiveness of the isolates was similar in the moisture experiments as previously described in the temperature experiments (Table 5). Notably, 99-15 was predominantly a seed rotter producing the lowest percent emergence in both studies. Isolates Rs91-1 and 98-0 also had high root rot ratings, whereas 99-8 and 9913 were among the least aggressive of the isolates evaluated in the moisture studies.

Seed treatment evaluations. The main effects of seed treatment and isolate were significant $(P<0.01)$ for final percent stand and root rot rating, and the effect of isolate on fresh root weight was also significant (Table 6). However, the majority of the variation was due to the main effect of isolate, as can be seen by the very high mean square values (Table 6). There were no seed treatment by isolate interactions for any of the measured parameters.
$R$. solani isolates $99-15$ and $99-17$ were the most aggressive and 99-8 the least aggressive on soybean cultivar Resnik. None of the seed treatments provided complete protection to the $R$. solani isolates tested. Generally, root rot ratings were lower and percent final stand was higher than the nontreated control, but the differences were not always significant due to variability within treatments (Table 7). For $R$. solani isolates $99-15$ and 99-17, which are seed rotters, the fungicides provided some protection. When averaged across all isolates, including the noninoculated control, Rival and Vitavax seed treatments resulted in significantly higher percent plant stands and root weights and lower root rot ratings than the nontreated control.

\section{DISCUSSION}

The only AG identified among the $44 R$. solani isolates collected in Ohio during 1998, 1999, and 2000 was AG-2-2 IIIB, similar to previous surveys in Ohio (9). $R$. solani AG-4 was the predominant AG iso- lated from soybean in Brazil (2), the Red River Valley (North Dakota and Minnesota; 10), and Florida (12). R. solani AG-4 is reported to be a common hypocotyl and seed pathogen of many crops (1). However, the reasons for the regional differences in predominance of AG type are unknown.

$R$. solani AG-2-2 IIIB grows well at $35^{\circ} \mathrm{C}$ (15). Recently, isolates of this AG group were recovered from soybeans in the Red River Valley (11). It was reported that the AG-2-2 IIIB isolates were less aggressive than the predominant AG-4 isolates when tested for pathogenicity on soybean (11). The authors proposed that the AG-2-2 IIIB may cause less disease due to the cool temperatures that occur in the Red River Valley. Our results do not fully support this hypothesis, in that soil temperatures in a range of 20 to $32^{\circ} \mathrm{C}$ may not be a critical factor in the infection process for isolates of AG-2-2 IIIB. There may be other factors associated with pathogenic fitness or propagule density with these AGs that cannot be explained by temperature alone. Among the AG-2-2 IIIB isolates tested in this study, there was a range of aggressiveness and pathogen type (causing seed rot versus root rot).

In this study, the ability of $R$. solani AG2-2 IIIB isolates to cause seedling and root disease in 'Resnik' soybean appeared to be only moderately related to soil moisture level. Similar results have been found previously in canola by Teo et al. (17), who observed that soil moisture had little effect on infection and disease severity as measured by seedling emergence and percent disease at maturity, although the incidence of adult plant infections was higher at high soil moisture. They (17) proposed that the higher incidence of disease at higher soil moisture may have followed from the related lower soil temperature that favored the growth of the $R$. solani isolate used in their study. Our study has shown that both low and excessive soil moisture (25 and $100 \%$ MHC) had a negative impact on soybean seedlings based on reduced root weights when compared with moisture levels of 50 and $75 \%$. Infection with $R$. solani may exacerbate the negative effects of low soil moisture on overall plant 
Table 6. Analysis of variance for the effects of five seed treatments (ST) and a nontreated control on soybeans inoculated with one of four Rhizoctonia solani isolates (I) or noninoculated in the greenhouse

\begin{tabular}{|c|c|c|c|c|c|c|c|}
\hline \multirow[b]{2}{*}{ Source } & \multirow[b]{2}{*}{ df } & \multicolumn{2}{|c|}{ Percent stand } & \multicolumn{2}{|c|}{ Root ratinga } & \multicolumn{2}{|c|}{ Fresh root weight } \\
\hline & & MS & $P$ & MS & $P$ & MS & $P$ \\
\hline Experiment (E) & 1 & 995.5 & 0.349 & 51.55 & $<0.001$ & 0.868 & 0.667 \\
\hline $\operatorname{Rep}(\mathrm{E})$ & 6 & $1,123.3$ & 0.431 & 0.69 & 0.721 & 5.278 & 0.348 \\
\hline ST & 5 & $4,436.1$ & 0.002 & 3.92 & 0.005 & 7.117 & 0.185 \\
\hline I & 4 & $29,071.7$ & $<0.001$ & 68.33 & $<0.001$ & 246.362 & $<0.001$ \\
\hline $\mathrm{ST} \times \mathrm{I}$ & 20 & $1,249.4$ & 0.347 & 1.36 & 0.266 & 3.446 & 0.786 \\
\hline Error & 204 & $1,131.5$ & & 1.14 & & 4.684 & \\
\hline
\end{tabular}

${ }^{a}$ Root rot rating scale was as follows: $1=$ no root rot; $2=1$ to $33 \%$ of roots with visible lesions or root rot; $3=$ approximately 33 to $50 \%$ of the roots rotted or damaged; $4=50$ to $80 \%$ of the roots rotted; and $5=$ preemergence damping-off and few if any roots.

Table 7. Percent stand, root rot rating, and fresh root weight with one of four Rhizoctonia solani isolates and a noninoculated control evaluated with six seed treatments and a nontreated control in the greenhouse

\begin{tabular}{lccc}
\hline Factor & Percent stand & Root rot rating & Root weight (g) \\
\hline Isolates & & & \\
Noninoculated & 95.5 & 1.2 & 6.6 \\
$99-8$ & 78.3 & 2.2 & 4.5 \\
$99-12$ & 41.2 & 3.5 & 1.8 \\
$99-15$ & 44.8 & 3.6 & 2.0 \\
$99-17$ & 37.0 & 4.1 & 1.4 \\
LSD $(P \leq 0.05)^{\mathrm{b}}$ & 12.4 & 0.4 & 0.9 \\
Seed treatment & & & \\
Rival & 76.6 & 2.5 & 4.0 \\
Stilletto & 57.7 & 2.9 & 3.1 \\
Vitavax & 66.7 & 2.7 & 3.4 \\
Maxim & 59.2 & 3.1 & 3.0 \\
T-22 & 52.5 & 3.1 & 3.0 \\
Nontreated & 43.5 & 3.3 & 3.0 \\
LSD $(P \leq 0.05)$ & 13.6 & 0.5 & NS \\
Mean & 59.4 & 2.9 & 3.3 \\
\hline
\end{tabular}

${ }^{a}$ Root rot rating scale was as follows: $1=$ no root rot; $2=1$ to $33 \%$ of roots with visible lesions or root rot; 3 = approximately 33 to $50 \%$ of the roots rotted or damaged; $4=50$ to $80 \%$ of the roots rotted; and 5 = preemergence damping-off and few if any roots.

b LSD stands for least significant difference as determined with Fisher's protected LSD at $P \leq 0.05$, and NS is not significant.

health, a premise that may help to explain these earlier findings (16).

Seed treatments, both fungicide and biological, are employed in crop production as a protectant against soilborne pathogens that may cause disease for the first few weeks after planting. If effective, there should be little to no disease development when postinfection stresses occur. In this study, no seed treatment prevented a reduction in stand or root rot consistently over the nontreated, inoculated control across all isolates. Martin et al. (9) in an earlier study demonstrated differences in sensitivity among $R$. solani AGs to different fungicides. All of the isolates were from the same AG in this study; thus we could not evaluate this factor. However, the seed treatment by isolate interaction was not significant, indicating that all of these isolates acted similarly with these treatments. The inoculum added to the soil in this study was colonized oat grain, which provides a lasting substrate, and probably served as a constant source of inoculum throughout the study. Seed treatments are applied to the soybean seed coat, which during germination is retained around the cotyledons as the plant emerges through the soil surface. The only fungicide that remains near the roots is what may have been washed off the seed coat during watering. If control is to be asserted by these treatments, sufficient concentrations of fungicides must be present on soybean seed at planting to provide adequate amounts of active ingredient in soil at the root zone. Following emergence, efficacy of seed treatments can readily be evaluated in greenhouse studies, although economic use of seed treatments should be determined with field evaluations over a number of years.

Epidemics of $R$. solani in field crops may not be a function of environment but related more to inoculum density, as a result of crop rotation (11), absence of competitors or antagonists. Crop rotations in much of the central region of the United States are primarily corn-soybeans. Two previous studies have demonstrated that corn is another host of both AG-2-2 IIIB and AG-4 (11,13), thus rotations with this crop may be of little value, especially in a 2-year rotation sequence.

$R$. solani can be a destructive pathogen on soybean. These results suggest that management measures aimed at influencing the soil temperature and moisture are unlikely to be successful due to the ability of this pathogen to infect soybeans over a broad temperature and moisture range. The potential of host resistance in soybean to $R$. solani has been demonstrated by others $(3,10)$ and should now be given serious consideration.

\section{ACKNOWLEDGMENTS}

We thank S. A. Miller, P. E. Lipps, and an anonymous reviewer for their thoughtful comments. Salaries and research support provided by state and federal funds appropriated to the Ohio Agricultural Research and Development Center, The Ohio State University.

\section{LITERATURE CITED}

1. Anderson, N. A. 1982. The genetics and pathogenicity of Rhizoctonia solani. Annu. Rev. Phytopathol. 20:329-347.

2. Bolkan, H. A., and Ribeiro, W. R. C. 1985 Anastomosis groups and pathogenicity of Rhizoctonia solani isolates from Brazil. Plant Dis. 69:599-601.

3. Bradley, C. A., Hartman, G. L., Nelson, R. L., Mueller, D. S., and Pedersen, W. L. 2001. Response of ancestral soybean lines and commercial cultivars to Rhizoctonia root and hypocotyl rot. Plant Dis. 85:1091-1095.

4. Carling, D. E. 1996. Grouping in Rhizoctonia solani by hyphal anastomosis reaction. Pages 37-47 in: Rhizoctonia Species: Taxonomy, Molecular Biology, Ecology, Pathology and Disease Control. B. Sneh, S. Jabaji-Hare, S. Neate, and G. Dijst, eds. Kluwer Academic Publishers, Dordrecht, Netherlands.

5. Kleinhenz, M. D., and Palta, J. P. 2002. Root zone calcium modulates the response of potato plants to heat stress. Physiol. Plant. 115:111-118

6. Krause, M. S., Madden, L. V., and Hoitink, H. A. J. 2001. Effect of potting mix microbial carrying capacity on biological control of Rhizoctonia damping-off of radish and Rhizoctonia crown and root rot of poinsettia. Phytopathology 91:1116-1123.

7. Lewis, J. A., and Papavizas, G. C. 1977. Factors affecting Rhizoctonia solani infection of soybeans in the greenhouse. Plant Dis. Rep. 61:196-200.

8. Liu, Z., and Sinclair, J. B. 1991. Isolates of Rhizoctonia solani anastomosis group 2-2 pathogenic to soybean. Plant Dis. 75:682-687.

9. Martin, S. B., Lucas, L. T., and Campbell, C. L. 1984. Comparative sensitivity of Rhizoctonia solani and Rhizoctonia-like fungi to selected fungicides in vivo. Phytopathology 74:778-781.

10. Muyolo, N. G., Lipps, P. E., and Schmitthenner, A. F. 1993. Anastomosis grouping and variation in virulence among isolates of Rhizoctonia solani associated with dry bean and soybean in Ohio and Zaire. Phytopathology 83:438-444.

11. Nelson, B., Helms, T., Christianson, T., and Kural, I. 1996. Characterization and patho- 
genicity of Rhizoctonia from soybean. Plant Dis. 80:74-80.

12. Ogoshi, A. 1987. Ecology and pathogenicity of anastomosis and intraspecific groups of Rhizoctonia solani Kühn. Annu. Rev. Phytopathol. 25:125-143.

13. Ploetz, R. C., Mitchell, D. J., and Gallaher, R. N. 1985. Characterization and pathogenicity of Rhizoctonia species from a reduced-tillage experiment multicropped to rye and soybean in Florida. Phytopathology 75:833-839.

14. Rizvi, S. S. A., and Yang, X. B. 1996. Fungi associated with soybean seedling disease in Iowa. Plant Dis. 80:57-60.
15. Sneh, B., Burpee, L., and Ogoshi, A. 1991. Identification of Rhizoctonia Species. American Phytopathological Society, St. Paul, MN.

16. Tachibana, H. 1968. Rhizoctonia solani root rot epidemic of soybeans in central Iowa 1967. Plant Dis. Rep. 52:613-614.

17. Teo, B. K., Yitbarek, S. M., Verma, P. R., and Morrall, R. A. A. 1988. Influence of soil moisture, seeding date, and Rhizoctonia solani isolates (AG-2-1 and AG-4) on disease incidence in canola. Can J. Plant Pathol. 10:151-158.

18. van Bruggen, A. H. C., Whalen, C. H., and Arneson, P. A. 1986. Emergence, growth, and development of dry bean seedlings in response to temperature, soil moisture, and Rhizoctonia solani. Phytopathology 76:568572.

19. Wrather, J. A., Stienstra, W. C., and Koenning, S. R. 2001. Soybean disease loss estimates for the United States from 1996 to 1998. Can. J. Plant Pathol. 23:122-131.

20. Yang, X. B. 1999. Rhizoctonia dampingoff and root rot. Pages 45-46 in: Compendium of Soybean Diseases, 4th ed. G. L. Hartman, J. B. Sinclair, and J. C. Rupe, eds. American Phytopathological Society, St. Paul, MN. 